\title{
ИЕРАРХИЧЕСКАЯ СТРУКТУРА НАНОПОРИСТОСТИ МЕКСИКАНСКИХ ПРИРОДНЫХ ЦЕОЛИТОВ ТИПА КЛИНОПТИЛОЛИТ
}

Итцель-Эрнандес Габриэла', gab.hdz.salgado@gmail.com

Эрнандес Мигель Анхель², vaga1957@gmail.com

Портильо Роберто ${ }^{2}$ portilloreyes@yahoo.com

\author{
Петрановский Виталий Павлович³, \\ vitalii@cnyn.unam.mx
}

Пестряков Алексей Николаевич ${ }^{4}$, pestryakov2005@yandex.ru

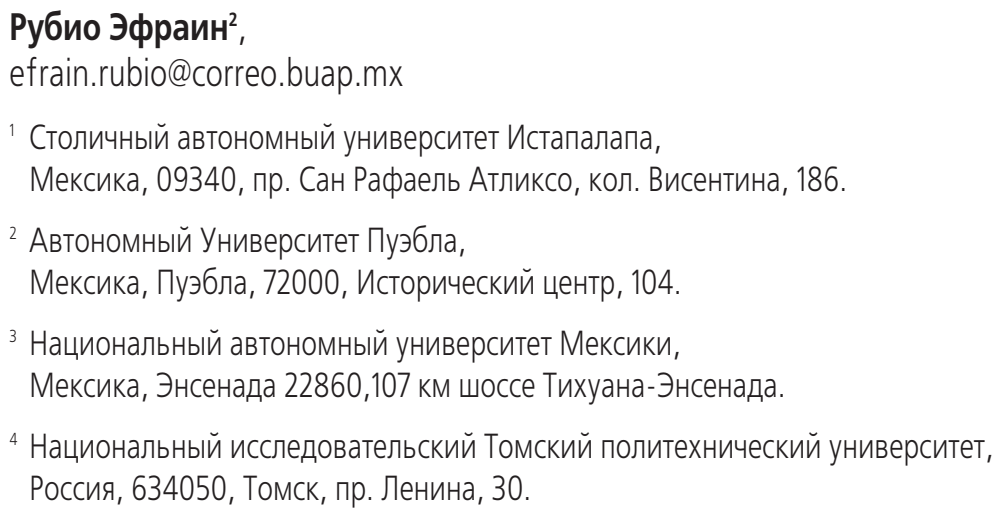

Актуальность исследования обусловлена большим количеством вновь открытых цеолитовых месторождений в Мексике. Для практического использования этих материалов требуются соответствующие экспериментальные модели, обеспечивающие достоверные и пригодные к использованию данные по каждому из заявленных месторождений.

Основной целью работы является оценка адсорбционной способности природных клиноптилолитных цеолитов из различных месторождений Мексики для оценки их нанопористости и наличия в них мезопористых пустот.

Объектами исследования являются цеолитовые туфы семи различных месторождений, расположенных в Мексике. Эти отложения слабо изучены и характеризуются сложным минеральным составом пород.

Методы исследования: цеолиты изучены методами рентгеноструктурного анализа, сканирующей электронной микроскопии, энергодисперсионной спектроскопии, термогравиметрии и дифференциальной сканирующей калориметрии. Все образцы были также изучены методом адсорбции $N_{2}$ для оценки площади поверхности всех исследованных цеолитов методом БЭТ, Ленгмюра и t-графиков. Общий объем пор оценивали в соответствии с правилом Гурсвича. Микропористость этих природных цеолитов измерялась методом адсорбции высокого разрешения с применением теории объемного заполнения микропор Дубинина-Астахова (D-A). Информация о распределении размеров микропор получена по данным изотермической адсорбции-десорбции.

Результаты. Нанопористость природных клиноптилолитных цеолитов из новых месторождений изучена традиционными экспериментальными методами, такими как DRX, SEM, EDS и HRADS N 2 при температуре кипения жидкого азота. Последним методом определены параметры текстуры, в которых микропоры оцениваются по t-графикам. Распределение нанопор определено с использованием недавно предложенного приближения, называемого дифференциальными кривыми адсорбции. Исследования методами термогравиметрии и дифференциальной сканирующей калориметрии показывают наличие трех типов адсорбированной воды: адсорбированной воды в макропорах, воды, адсорбированной во внешней области цеолита (мезопоры), и воды, адсорбированной в микропорах. Такое поведение подтверждается адсорбцией $N_{2}:$ микропористым заполнением, многослойным заполнением на внешней поверхности цеолитового туфа и проявлением капиллярной конденсации, возникающей в макропорах.

\section{Ключевые слова:}

Природный цеолит, клиноптилолит, характеристические энергии адсорбции, нанопористость, мезопористость.

\section{Введение}

Клиноптилолит (по данным Международной Цеолитной Ассоциации структурный код этого цеолита HEU) является наиболее распространенным цеолитом в мире, а также в Мексике [1-3]. За- регистрированые клиноптилолитовые месторождения можно найти в различных местах в Мексике; наиболее известны из них открытые месторождения в Этла, Оахака [2]; Сан-Габриель-Чилак и Теуакан, Пуэбла [4, 5]; Сан-Франциско, Гуанахуа- 
то; Эскалерильяс и Сан-Лукас, Сан-Луис-Потоси [6]; Сан-Педро-Урес, Сан-Хуан-Гуаймас [7] и ЭльКахон в Сонора [8]. Для детального изучения были отобраны пробы семи из этих месторождений. Клиноптилолит в различных катионных формах является основной фазой этих пород, но, как и любой природный материал, содержит определенное количество примесей в их составе.

Все цеолиты имеют развитую внутреннюю поверхность, доступную для адсорбции благодаря наличию однородных по размерам каналов и полостей, которые равномерно распределены по всему объему $[9,10]$. Обычно при обсуждении цеолитов и способов их применения в основном рассматривают их первичную пористость, формируемую за счет их кристаллической структуры. Первичная пористая структура, образованная пустотами между структурными элементами кристаллов, является постоянной характеристикой каждого типа цеолита. Структура клиноптилолита образует трехмерную канальную систему (рис. 1). Размер входных окон, образованных кислородными мостиками, определяет доступность внутренних полостей цеолитов для адсорбированных молекул. Смена типа обменных катионов может изменить размер окон $[5,10]$.

При описании пористых материалов весьма полезно учитывать понятия первичной и вторичной пористых структур $[10,11]$. Первичная пористость цеолитов зависит от кристаллической структуры и состава цеолита. Как правило, эта поверхность в пределах нескольких сотен квадратных метров на грамм цеолита. Площадь внешней поверхности, более известная как мезопоры, составляет небольшой процент от общей доступной площади. Тем не менее, эта вторичная пористость может быть очень важной в некоторых случаях их применения, где используются молекулы большого размера. Нанопористость этих материалов можно оценить с помощью адсорбционных исследований высокого разрешения молекул различных размеров, а также другими методами [12].
Использование природных цеолитов весьма разнообразно, но их эффективность часто обсуждается в сравнении с их синтетическими аналогами. Сообщалось $[10,13,14]$, что природные осадочные цеолиты не могут заменить синтетические цеолиты в некоторых важных промышленных применениях, поскольку они имеют ограниченную химическую чистоту и многофазный состав. Тем не менее, другие авторы отмечают, что уже существуют многочисленные области применения природных цеолитов, особенно клиноптилолита, который может выступать в качестве лекарственных средств, $[15,16]$, препаратов сопутствующей терапии (коадъютантов) [17], носителем катализаторов и фармацевтических препаратов [18, 19], то есть в таких важных областях, как гетерогенный катализ, биология и медицина, как для фундаментальных, так и для прикладных исследований.

Однако, несмотря на всевозрастающее применение цеолитов, более широкое их использование постепенно усложняется из-за ограничений, накладываемых размерами микропор. С учетом этого, для преодоления диффузионных ограничений современная стратегия получения синтетических материалов предлагает образование более коротких диффузионных путей через создание мезопор, в дополнение $\kappa$ внутренней микропористости $[20,21]$. Полученные в этой связи усовершенствования вызвали большой интерес к использованию цеолитов, демонстрирующих существование иерархической структуры, то есть таких материалов, в которых, помимо нанопор, существует и мезопористая система.

Осознание того, что природные цеолиты могут работать во многих неожиданных секторах (например, медицина), значительно расширило сферу их применения, открыв новые горизонты.

В работе была изучена адсорбционная способность природных клиноптилолитных цеолитов из различных месторождений Мексики, чтобы определить их нанопористость и оценить, обладают ли
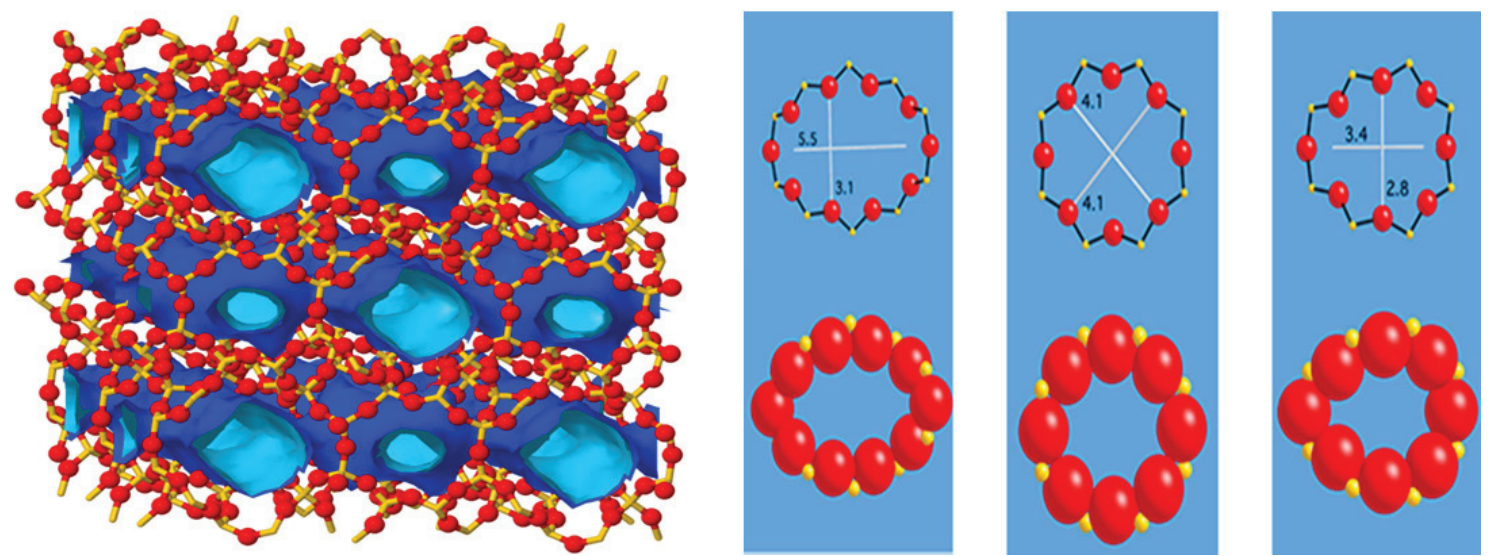

Рис. 1. Структура клиноптилолита. Слева - трехмерное моделирование, схематически показывающее ионы Si и О (желтые и красные, соответственно) и внутреннюю поверхность каналов (светло-голубая поверхность). Справа - кольца во входных отверстиях каналов клиноптилолита

Fig. 1. Structure of clinoptilolite. Left side - three-dimensional simulation that schematically shows Si and O ions (yellow and red bolls, respectively) and internal surface of channels, light-blue surface. Right side - rings in the openings of clinoptilolite channels 
они мезопористыни пустотами. Для оценки характерных энергий адсорбции Е построены графики высокого разрешения в соответствии с моделью Дубинина-Астахова (D-A).

\section{Материалы и методы}

Для данной работы были выбраны клиноптилолиты из мексиканских месторождений, таких как Этла, Оахака (Е-0), Эскалерильяс, Сан-Луис-Потоси (E-SLP), Сан-Хуан-Гуаймас, Сонора (SJG-S), Эль-Кахон, Сонора (C-S), Сан-Франциско, Гуанахуато (SF-G), Сан-Габриэль-Чилак, Пуэбла (SGCH-P) и Теуакан, Пуэбла (T-P). Образцы маркировались по месту происхождения.

Рентгенограммы определялись с помощью дифрактометра Bruker D8 с использованием Niфильтрованного $\mathrm{Cu} \mathrm{K}_{\alpha}$-излучения и сравнивались с соответствующими базами JCCPD для идентификации фаз, присутствующих в образцах. Изображения сканирующей электронной микроскопии были получены с помощью электронного микроскопа Vega Tescan, модель JSM-5300, оснащенного энергодисперсионным спектрометром (EDS) зонд, который позволяет полуколичественное определение локального состава. Термогравиметрический анализ (ТГА) и Дифференциальную сканирующую калориметрию (ДСК) проводили с помощью теплового анализатора NETSCH STA $449 \mathrm{~F} 3$ со скоростью нагрева $10{ }^{\circ} \mathrm{C}$ мин $^{-1}$ в интервале температур $30-1000{ }^{\circ} \mathrm{C}$.

Для текстурных исследований использовались газы $\mathrm{N}_{2}$ и Не сверхвысокой чистоты (>99,999 \%), поставляемые INFRA Corp. Все изотермы адсорбции $\mathrm{N}_{2}$ измеряли при температуре кипения жидкого азота $(76,4 \mathrm{~K}$ на высоте 2200 м над уровнем моря в городе Пуэбла, Мексика) в автоматической системе объемной адсорбции (Quantachrome AutoSorb-1LC). Изотермы адсорбции $\mathrm{N}_{2}$ определяли в интервале относительных давлений $\mathrm{p} / \mathrm{p}^{0}$ от $10^{-6}$ до 0,995. Давление насыщения $\mathrm{p}^{0}$ непрерывно регистрировалось при адсорбционно-десорбционных измерениях. Из всех анализируемых образцов были отобраны порошки с размером частиц, соответствующим сетке 60-80 mesh. До проведения сорбционных экспериментов образцы дегазируются при $350{ }^{\circ} \mathrm{C}$ в течение 20 ч при давлении менее $10^{-6}$ мбар.

По данным адсорбции $\mathrm{N}_{2}$ в интервале $\mathrm{p} / \mathrm{p}^{0}$ от 0,04 до 0,2 , оценивали площади поверхности по методам БЭТ [22], Ленгмюра [23] и t-графиков [24] всех исследованных цеолитов. Общий объем пор, $\mathrm{V}_{\Sigma}$, оценивали по правилу Гурсвича на основе адсорбированного объема при относительном давлении $\mathrm{p} / \mathrm{p}^{0}=0,95$ и рассчитывали как объем жидкости [25]. Микропористость этих природных цеолитов измерялась методом адсорбции высокого разрешения D-A в диапазоне $\mathrm{p} / \mathrm{p}^{0}=10^{-6}-0,2$ [26]. Информация о распределении размеров микропор получена по данным изотермической адсорбции-десорбции с использованием метода D-A и дифференциальных кривых адсорбции DAC [27].

\section{Результаты и обсуждение}

DRX. На рис. 2 показаны дифракционные картины изучаемых природных цеолитов. Фазы, наблюдаемые для каждого образца, перечислены в табл. 1. В этих образцах наблюдается присутствие клиноптилолита (JCPDS карты 3-0427) и, в меньших количествах, такие примеси, как морденит (JCPDS 29-1257), монтмориллонит (JCPDS 29-1498), кварц (интенсивный пик на 27 $2 \theta$ (JCPDS 3-0427). Реже наблюдаются следы таких минералов, как слюда, ортоклаз, кристобалит, кальцит-магнезит. Наиболее характерные пики кристаллического клиноптилолита наблюдаются для следующих углов дифракции $2 \theta: 9,86^{\circ}, 11,06^{\circ}, 13,03^{\circ}, 14,82^{\circ}, 16,86^{\circ}$, $17,2^{\circ}, 19,04^{\circ}, 22,35^{\circ}, 25,04^{\circ}, 28,09^{\circ}, 31,71^{\circ}, 32,67^{\circ}$, в то время как для морденита типичные углы дифракции $2 \theta: 6,59^{\circ}, 13,46^{\circ}, 19,70^{\circ}, 22,25^{\circ}, 25,69^{\circ}, 26,25^{\circ}$, $27,66^{\circ}$ и $30,99^{\circ}$. Из этого рисунка видно, что пики клиноптилолита преобладают для всех образцов.

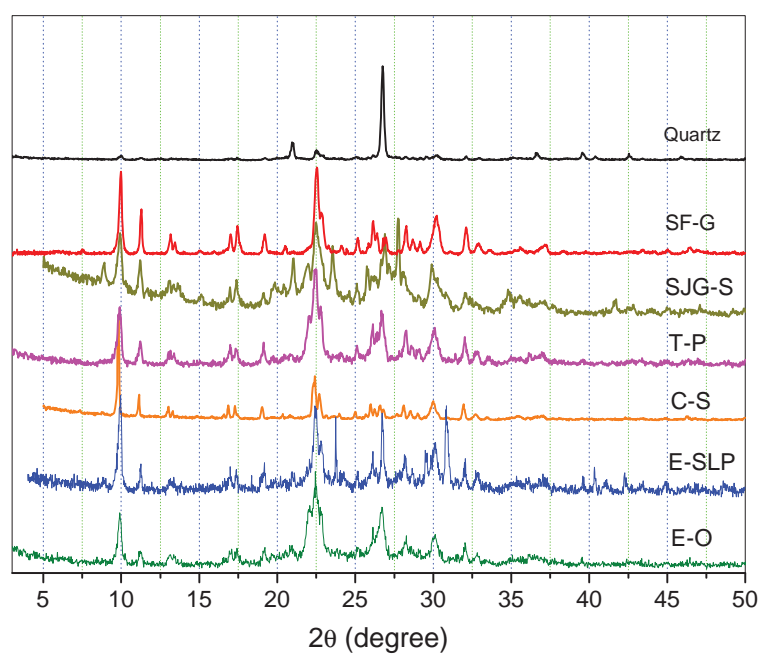

Рис. 2. XRD спектры клиноптилолитов. В качестве эталона используется образец $\alpha$-кварца $\left(2 \theta=27,5^{\circ}\right)$

Fig. 2. XRD patterns of clinoptilolite zeolites. A sample of $\alpha$-quartz $\left(2 \theta=27,5^{\circ}\right)$ is used as the reference

СЭМ. Растровые электронно-микроскопические изображения выбранного в качестве примера цеолита SJG-S показаны на рис. 3. Кристаллы клиноптилолита в большинстве имеют форму тонких пластинчатых кристаллов с размерами в диапазоне 1,5-9 мкм. На рис. 3, $b$ показаны различные формы кристаллов. Данные химического анализа, оцененные методом EDS, представлены в табл. 2. Как и ожидалось для природных материалов, содержание обменных катионов ( $\mathrm{Na}, \mathrm{K}, \mathrm{Ca}, \mathrm{Mg})$ в различных клиноптилолитах существенно изменяется.

TGA/DSC. Кривые ТГA для природных клиноптилолитов показаны на рис. $4, a$. В низкотемпературной части $\left(<100{ }^{\circ} \mathrm{C}\right)$ этих кривых наблюдается десорбция физадсорбированной воды с поверхности зерен и из макропор в частицах порошка. Средняя часть кривых (В), в интервале 100-200 ${ }^{\circ} \mathrm{C}$, является областью десорбции «слабосвязанной цеолитной воды» из мезопор. Высоко- 
Известия Томского политехнического университета. Инжиниринг георесурсов. 2018. Т. 329. № 10. 107-117

Итцель-Эрнандес Г. и др. Иерархическая структура нанопористости мексиканских природных цеолитов типа клиноптилолит

Таблица 1. Минеральный состав природных цеолитовых туфов из Мексики

Table 1. Source and mineralogy of natural clinoptilolite tuffs from Mexico

\begin{tabular}{|c|c|c|}
\hline $\begin{array}{l}\text { Образец } \\
\text { Sample }\end{array}$ & $\begin{array}{l}\text { Месторождение } \\
\text { Localization }\end{array}$ & $\begin{array}{c}\text { Фазовый состав (данные РФА) } \\
\text { Phase composition (X-Ray phase analysis data) }\end{array}$ \\
\hline $\mathrm{E}-\mathrm{O}$ & $\begin{array}{l}\text { Этла, Охака } \\
\text { Etla, Oахаса }\end{array}$ & $\begin{array}{c}\text { Клиноптилолит-Na >>Mорденит, Биотитовая слюда>Плагиоклаз>Кварц } \\
\text { Clinoptilolite-Na>>Mordenite, biotite mica>plagioclase>Quartz }\end{array}$ \\
\hline E-SLP & $\begin{array}{l}\text { Эскалерильяс, Сан-Луис-Потоси } \\
\text { Escalerillas, San Luis Potosi }\end{array}$ & $\begin{array}{l}\text { Клиноптилолит-K>Moнтмориллонит>Кварц } \\
\text { Clinoptilolite-K>Montmorillonite }>\text { Quartz }\end{array}$ \\
\hline T-P & $\begin{array}{l}\text { Теуакан, Пуэбла } \\
\text { Tehuacan, Puebla }\end{array}$ & $\begin{array}{l}\text { Клиноптилолит-Са, Морденит, Кварц } \\
\text { Clinoptilolite-Ca, Mordenite, Quartz }\end{array}$ \\
\hline SGCH-P & $\begin{array}{l}\text { Сан-Габриэль-Чилак, Пуэбла } \\
\text { San Gabriel Chilac, Puebla }\end{array}$ & $\begin{array}{l}\text { Клиноптилолит>>Кварц, Морденит, Альбит, Кристобалит } \\
\text { Clinoptilolite >> Quartz, Mordenite, albite, cristobalite. }\end{array}$ \\
\hline C-S & $\begin{array}{l}\text { Эль-Кахон, Сонора } \\
\text { Cajón, Sonora }\end{array}$ & $\begin{array}{c}\text { Клиноптилолит-К>>Кварц } \\
\text { Clinoptilolite-K>>Quartz }\end{array}$ \\
\hline$S F-G$ & $\begin{array}{l}\text { Сан-Франциско, Гуанахуато } \\
\text { San Francisco, Guanajuato }\end{array}$ & $\begin{array}{c}\text { Клиноптилолит-Са>>Кварц>Кальцит (следы) } \\
\text { Clinoptilolite-Ca>>Quartz>Calcite-magnesium traces }\end{array}$ \\
\hline
\end{tabular}
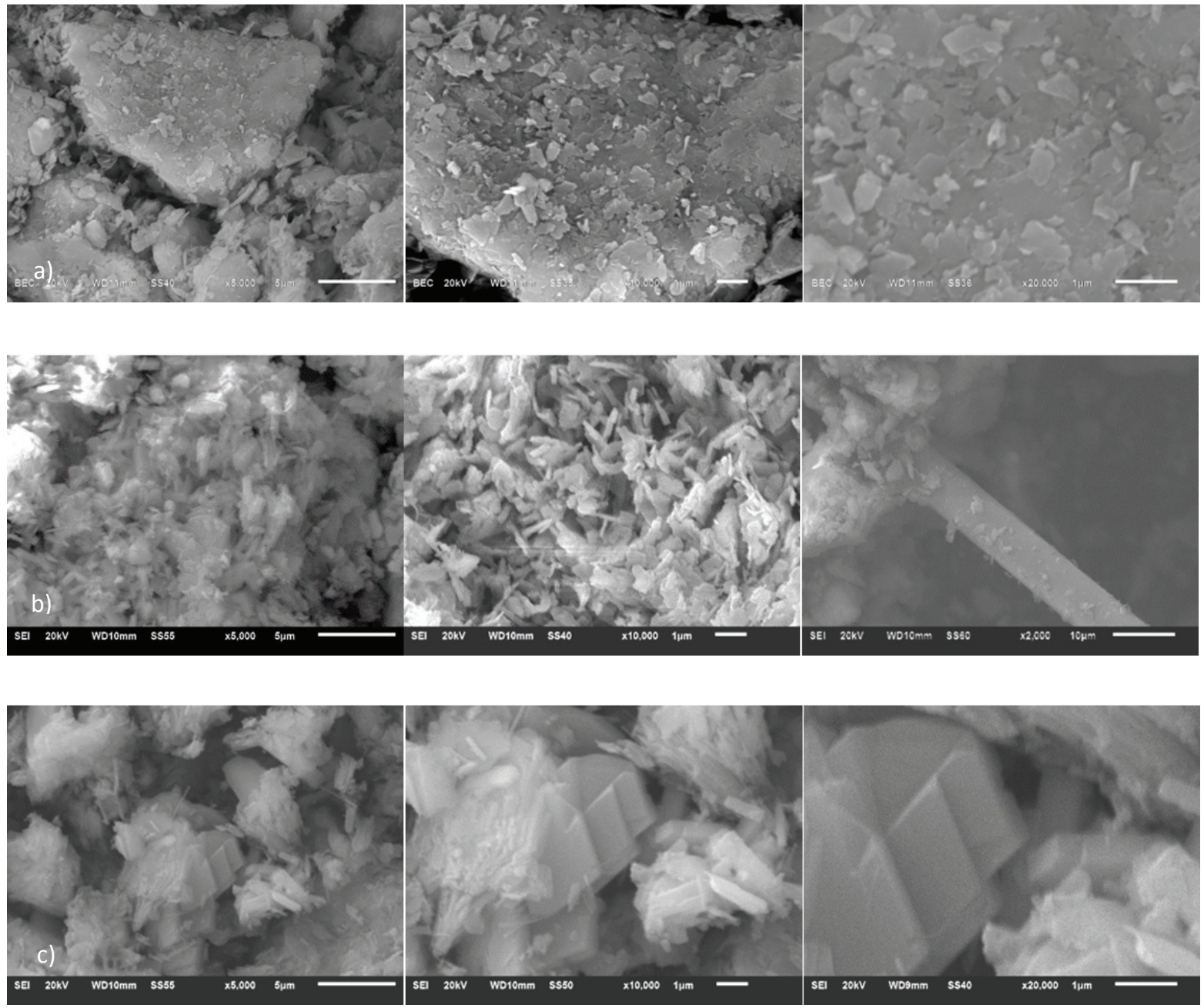

Рис. 3. Растровые электронно-микроскопические изображения цеолита SJG-S

Fig. 3. Scanning electron microscopy images of zeolite SJG-S 
температурная часть кривых (C) в диапазоне 200-500 ${ }^{\circ} \mathrm{C}$ представляет собой медленную десорбцию «цеолитной воды» из микропористых каналов образцов цеолитов. В литературе эта вода известна как «сильно связанная цеолитная вода». Наконец, в интервале $500-900{ }^{\circ} \mathrm{C}$ вес всех образцов был постоянным в пределах точности измерений. Результаты термогравиметрического анализа исследуемых клиноптилолитов приведены в табл. 3. Относительная потеря веса природных клиноптилолитов, проанализированных этим методом, соответствует известным литературным данным [28].

Таблица 2. Химический состав клиноптилолитов (масс. \%) по данным EDS

Table 2. Clinoptilolite chemical composition (wt. \%), based on EDS data

\begin{tabular}{|c|c|c|c|c|c|c|c|c|c|c|c|}
\hline 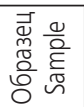 & $\stackrel{O^{2}}{n}$ & $\stackrel{O_{N}^{m}}{\mathbb{L}}$ & $\begin{array}{l}O^{m} \\
\mathcal{W}^{m}\end{array}$ & ণ্তি & $\stackrel{\circ}{g^{n}}$ & $\begin{array}{l}\overbrace{}^{N} \\
\stackrel{2}{Z}\end{array}$ & $\underset{\underset{\sim}{0}}{\circ}$ & $\stackrel{\circ}{\circ}$ & ষ & $\frac{\bar{a}}{i n}$ & $\overline{\mathrm{G}}$ \\
\hline $\mathrm{E}-\mathrm{O}$ & 69,91 & 10,94 & 0,20 & 0,70 & 0,20 & 3,80 & 2,80 & Нет & Нет & 5,63 & 111,4 \\
\hline T-P & 67,07 & 11,31 & 1,21 & 3,57 & 0,68 & 2,90 & 0,52 & Нет & Нет & 5,93 & 6,8 \\
\hline E-SLP & 64,70 & 11,90 & 2,28 & 2,03 & 0,78 & 0,74 & 5,10 & Нет & Нет & 5,43 & 12,5 \\
\hline C-S & 74,49 & 14,95 & Нет & 2,63 & 1,00 & 2,63 & 2,38 & 0,36 & 1,50 & 4,98 & Нет \\
\hline SF-G & 64,46 & 12,28 & 1,13 & 2,59 & 0,50 & 0,54 & 3,07 & Нет & 0,25 & 5,24 & 13,7 \\
\hline SJG-S & 66,60 & \begin{tabular}{|l}
11,12 \\
\end{tabular} & 1,57 & 2,01 & 0,50 & 1,20 & 1,30 & Нет & Нет & 5,28 & 15,7 \\
\hline SGCH-P & \begin{tabular}{|l|l}
64,97 \\
\end{tabular} & 12,32 & Нет & $\mid 1,71$ & 1,30 & 1,80 & 4,14 & Нет & 1,616 & \begin{tabular}{|l}
5,27 \\
\end{tabular} & Нет \\
\hline
\end{tabular}

Кривые ДСК для тех же образцов показаны на рис. $4, b$. Десорбция трех типов воды, наблюдаемая методом ТГА, должна была дать три эндотермических пика ДСК. Низко-, средне- и высоко-температурные пики соответствуют десорбции физисорбированной воды (А), слабосвязанной цеолитной воды (Б) и сильносвязанной цеолитой воды (C), соответственно. Из этого графика видно, что высота пиков зависит от катионной природы каждого из анализируемых цеолитов. Поскольку катионообменные клиноптилолиты обладают широким спектром адсорбционных характеристик, модификация имеющихся природных материалов методами ионного обмена в перспективе делает их пригодными для применения в различных областях, таких как осушение и адсорбционное разделение газовых смесей $[29,30]$. Результаты ДСК подтверждают то, что было ранее обнаружено с помощью анализа ТГА. Также эти наблюдения подтверждают, что существенной десорбции воды выше $500{ }^{\circ} \mathrm{C}$ не происходит и что за счет наличия различных типов пористости в клиноптилолите существует три типа воды, которые последовательно десорбируются при все более высоких температурах [31, 32].

Таблица 3. Термогравиметрический анализ природных клиноптилолитов (вес. \%)

Table 3. Thermogravimetric analysis of natural clinoptilolites (wt. \%)

\begin{tabular}{|c|c|c|c|c|c|}
\hline 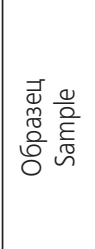 & 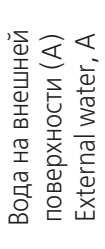 & 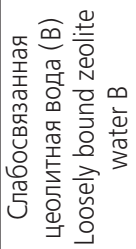 & 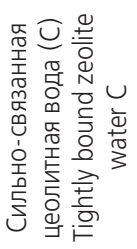 & 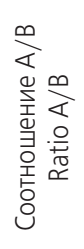 & 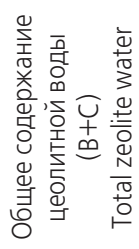 \\
\hline C-S & 3,515 & 3,933 & 8,616 & 0,894 & 12,549 \\
\hline $\mathrm{E}-\mathrm{O}$ & 2,658 & 3,652 & 6,060 & 0,728 & 9,712 \\
\hline E-SLP & 4,416 & 3,085 & 7,585 & 1,431 & 10,67 \\
\hline T-P & 2,755 & 3,274 & 8,075 & 0,841 & 11,349 \\
\hline SF-G & 4,549 & 3,898 & 8,708 & 1,167 & 12,606 \\
\hline SGCH-P & 1,794 & 2,318 & 4,794 & 0,774 & 7,112 \\
\hline SJG-S & 2,209 & 2,121 & 3,816 & 1,041 & 5,937 \\
\hline
\end{tabular}
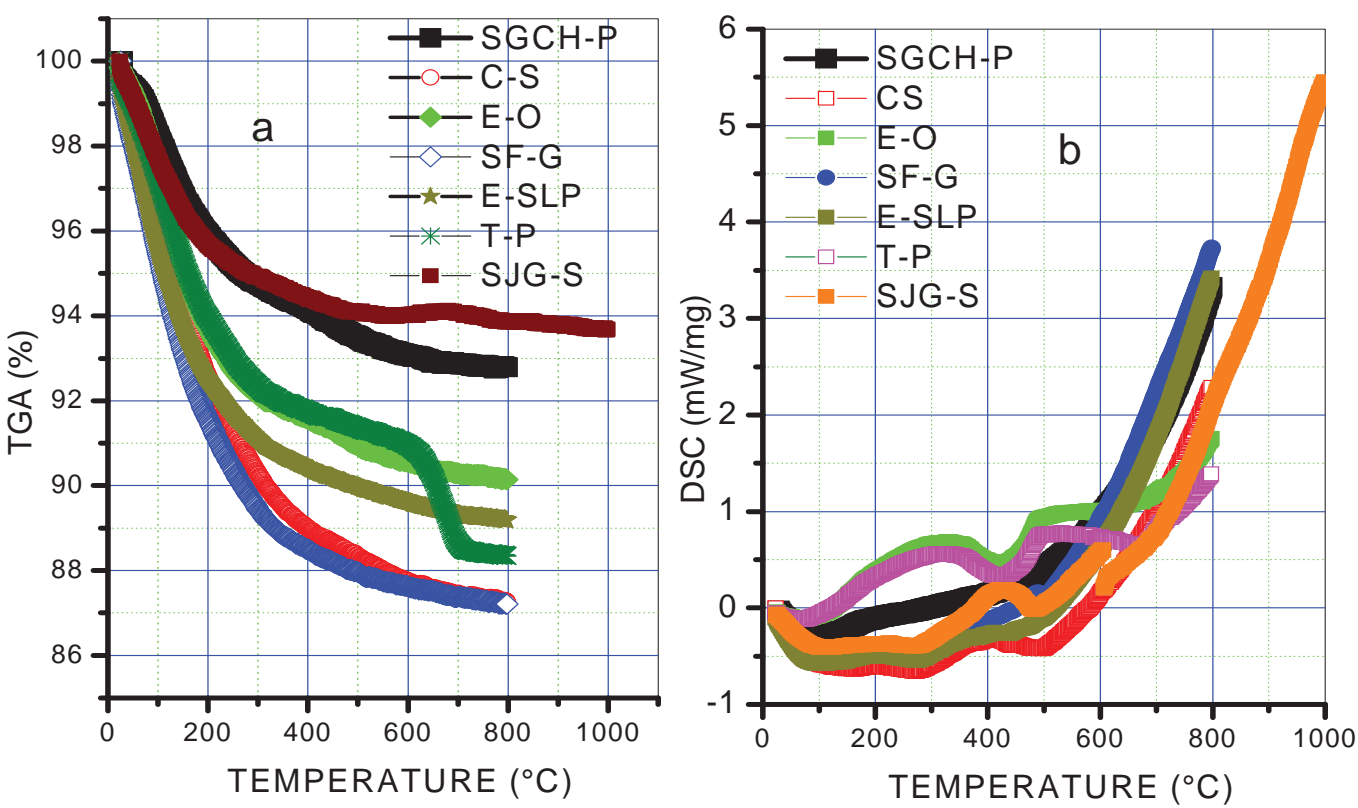

Рис. 4. Термический анализ природных клиноптилолитов: а) термогравиметрические данные; b) дифференциальная сканирующая калориметрия

Fig. 4. Thermal analysis for natural clinoptilolites: a) thermogravimetric data; b) Differential Scanning Calorimetry 

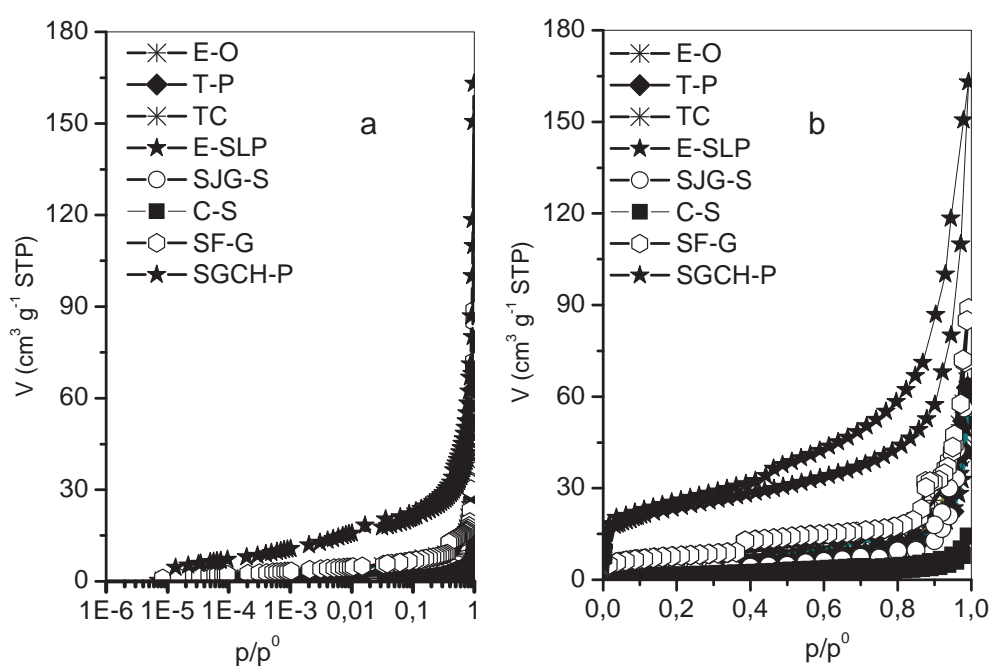

Pис. 5. Изотермы адсорбции $N_{2}$ при 77 К на клиноптилолитах в логарифмической шкалер $/ p^{\circ}$ (a) и изотермы адсорбции $N_{2}$ при 77 К (b)

Fig. 5. a) $\mathrm{N}_{2}$ adsorption isotherms at $77 \mathrm{~K}$ on clinoptilolite in logarithmic $\left.\mathrm{p} / \mathrm{p}^{0} \mathrm{scale} ; b\right) \mathrm{N}_{2}$ adsorption isotherms at $77 \mathrm{~K}$ on clinoptilolite

Адсорбция $\mathrm{N}_{2}$. Изотермы адсорбции $\mathrm{N}_{2}$ (относительное давление $\mathrm{p} / \mathrm{p}^{0}$ против адсорбированного объема в см$^{3}$ на грамм цеолита при стандартных условиях) на природных клиноптилолитах показаны на рис. 5, a. Изотермы адсорбции в логарифмической шкале $\mathrm{p} / \mathrm{p}^{0}$ показаны на рис. $5, b$. Наконец, на рис. 6 показаны t-графики высокого разрешения, описывающие заполнение микропор. Все $\mathrm{N}_{2}$ изотермы относятся к типу IV или VI по классификации ИЮПАК [33]. Результаты текстурного анализа этих кривых (БЭТ, Ленгмюр, t-графики, правило Гурсвича и объемы микропор $\mathrm{W}_{0}$ ) приведены в табл. 4. Заполнение узких и крупных микропор в этих наноструктурированных материалax может быть подтверждено путем анализа t-графиков высокого разрешения (рис. 6), начиная с низких относительных давлений (т. е. от $10^{-5}$ ).

Специфические сорбционные характеристики изученных минеральных образцов описаны ниже. Существуют некоторые существенные различия в форме t-графиков для природных цеолитов, главным образом в случае образцов SGCH-P и SF-G (рис. 6). При очень низких значениях $\mathrm{p} / \mathrm{p}^{0}$ наблюдается выраженное искажение формы изотермы, что можно объяснить усиленным взаимодействием адсорбент-адсорбат в порах молекулярных размеров, т. е. процессом заполнения микропор, происходящим в ультрамикропорах, $\mathrm{t}=0,15-0,3$. Данный тип t-графиков характерен для микропористых адсорбентов, имеющих широкий диапазон размеров пор и дающих начало двум и более отдельным стадиям заполнения микропор, зонам $\mathrm{t}=0,3-0,55$ и $0,55-0,95$. Сильная необратимая адсорбция молекул возможна в узкостях (углах, в которых встречаются стенки пор) микропористых образований. В случае цеолитов некоторые углы будут располагаться на пересечениях каналов пор, где предсказаны сильные взаимодействия адсорбат-адсорбент [34]. Такие взаимодействия должны быть точно определены с целью воспроизведения экспериментально измеренной адсорбции и допускать дальнодействующие дисперсионные взаимодействия атомов цеолитного каркаса с разновидностями веществ, адсорбированными на активном центре [35].

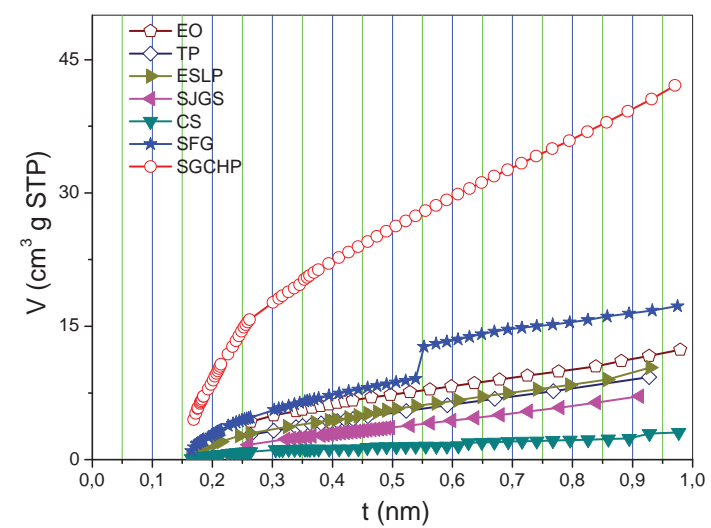

Рис. 6. литах

Fig. 6. t-plots for $\mathrm{N}_{2}$ adsorption at $77 \mathrm{~K}$ on clinoptilolite-zeolites

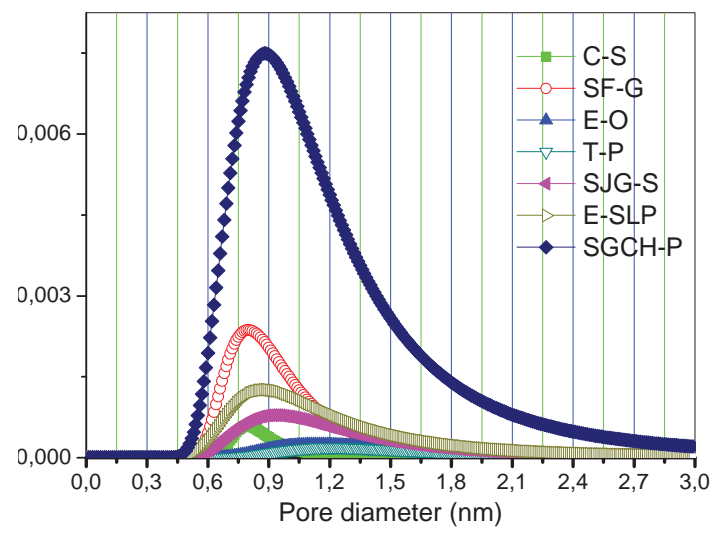

Рис. 7. Распределение по размерам нанопор клиноптилолита по уравнению Дубинина-Астахова

Fig. 7. Nanopore size distribution of clinoptilolite from Dubinin-Astakhov equation 


\section{Распределение нанопор по размерам,} вычисленное методами D-A и DAC

D-A подход. Соответствующее распределение нанопор по размерам было рассчитано из изотерм адсорбции-десорбции $\mathrm{N}_{2}$, и результаты этих оценок показывают, что наноканалы распределены равномерно и имеют диаметры в пределах от 1,14 до 0,79 нм (рис. 7 ). Из рисунка видно, что положение максимума сигнала коррелирует с содержанием $\mathrm{Al}$ в структуре изучаемых природных цеолитов (11-й столбец, табл. 2). В этой же таблице приведены оптимизированные значения $\mathrm{W}_{0}$, объема микропор, а также значения характерной энергии адсорбции $\mathrm{E}_{0}$, полученные из уравнения D-A. Полученные результаты показывают, что по мере роста концентрации $\mathrm{Al}$ происходит увеличение открытости и ширины нанопор.

Значения $\mathrm{E}_{0}$, полученные этим методом, возрастают при уменьшении концентрации $\mathrm{Al}$, но также зависят и от вида ионообменных катионов. Другими словами, полученные значения показывают зависимость $\mathrm{E}_{0}$ от отношения $\mathrm{Si} / \mathrm{Al}$ в составе цеолитного каркаса. Изоморфное замещение четырехвалентного Si (IV) трехвалентными атомами Al (III) в тетраэдрических единицах кристаллической структуры цеолита приводит к появлению несбалансированного отрицательного заряда и наличию неструктурных зарядо-балансирующих обменных катионов, расположенных в пустотах структуры цеолита. Очевидно, что изменения в соотношении $\mathrm{Si} / \mathrm{Al}$ и в виде обменных катионов изменяют адсорбционный потенциал. Концентрация атомов $\mathrm{Al}$ и электростатическое взаимодействие с катионами влияют на электрические поля в порах цеолита [10], а следовательно, и на взаимодействие с сорбированными молекулами.

Дифференциальные адсорбционные кривые (DAC). Такие кривые могут быть получены пря- мым дифференцированием t-графика; они показаны на рис. 8, $a$, б. На рис. $8, a$ видно, что дифференциальные кривые адсорбции клиноптилолитов SF-G, SGCH-P, SJG-S и E-O дают очень узкое тримодальное распределение значений, близких к $\mathrm{t}=0,8,1,15$ и 1,8 нм. Такая четкость обусловлена наличием в данном цеолите микропор одинакового размера, то есть пор молекулярных размеров, имеющихся в каналах А, В и С клиноптилолита [36]. Можно отметить, что наиболее острые и узкие пики соответствуют цеолитам SF-G и SGCH-P. Эти цифры также показывают, что для цеолитов C-S, E-SLP и T-P узкие пики распределения дифференциальных кривых адсорбции относительно малы по интенсивности. В заключительной части DAC распределения становятся широкими (т. е. не очень острые пики), что отражает наличие мезопор, со значениями $t$ в интервале диаметров $1,2-3,4$ нм.

Подводя итоги, можно отметить, что была исследована нанопористость богатых клиноптилолитами туфов семи мексиканских месторождений с использованием методов DRX, SEM, EDS, TGA, DSC и адсорбции $\mathrm{N}_{2}$. Результаты DRX свидетельствуют о преобладающем присутствии клиноптилолита и небольших количествах морденита, наряду с незначительными количествами других минеральных примесей, которые меняются от месторождения к месторождению. SEM-изображения этих цеолитов показывают типичные для клиноптилолита кристаллы пластинчатой формы с размерами в диапазоне 1,5-9 мкм. Данные химического анализа, полученные с помощью ICP, показывают, что химический состав цеолитов значительно меняется в зависимости от месторождения. Десорбция воды, изученная методами ТГА и ДСК, показала наличие трех типов воды, соответствующих трем пористым подсистемам. Низко-, средне- и вы-
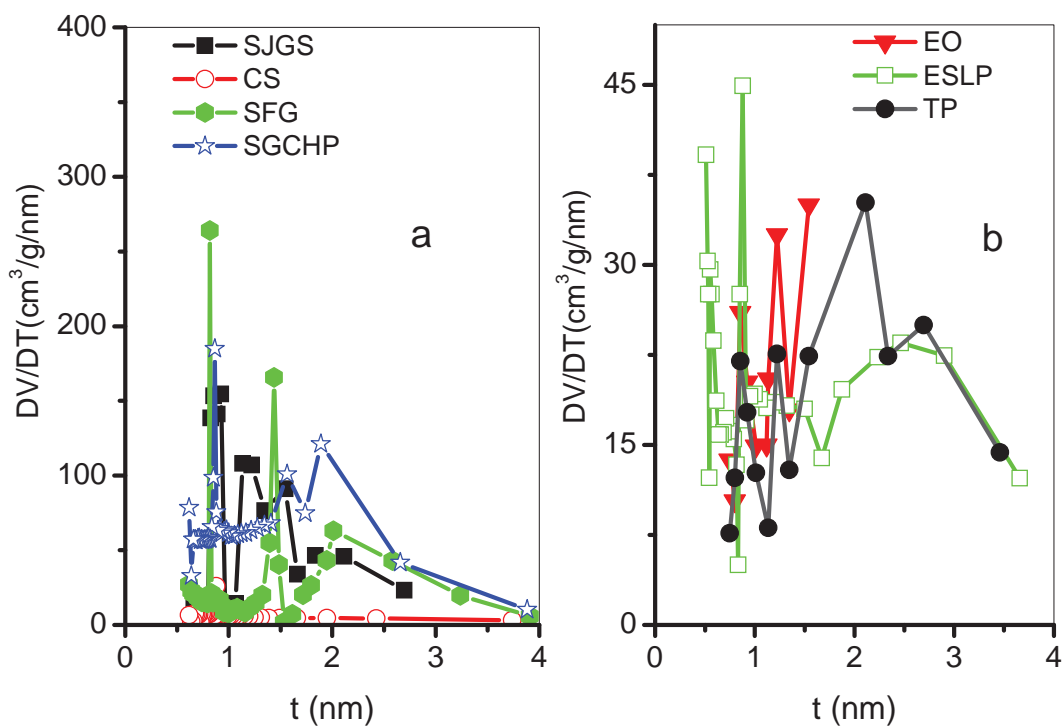

Рис. 8. Дифференциальные кривые адсорбции клиноптилолитов: а) SJG-S, C-S, SF-G, SGCH-P; b) E-O, E-SLP, T-P

Fig. 8. Differential curves of adsorption of clinoptilolite-zeolites: a) SJG-S, C-S, SF-G, SGCH-P; b) E-O, E-SLP, T-P 
соко-температурные пики соответствуют десорбции воды с внешней поверхности минеральных зерен (А), слабосвязанной цеолитной воды их мезопор (B), и сильносвязанной воды (C), соответственно. Изотермы $\mathrm{N}_{2}$ имеют тип IV или VI в соответствии с номенклатурой ИЮПАК. Заполнение узких и крупных микропор в этой иерархической структуре может быть подтверждено анализом t-графиков высокого разрешения. Однако наблюдаются существенные различия в форме t-графиков для этого набора природных клиноптилолитов, главным образом для образцов SGCH-P и SF-G. Этот тип t-графиков характерен для микропористых адсорбентов, имеющих широкий диапазон размеров пор, что приводит к двум или более отдельным стадиям заполнения микропор, зонам $\mathrm{t}=0,3-0,55$ и $0,55-0,95$. Сильная необратимая адсорбция молекул возможна в узкостях (углах, в которых встречаются стенки пор) микропористых образований. Наконец, дифференциальные кривые адсорбции в клиноптилолитах SF-G, SGCH-P, SJG-S и E-O дают очень узкие тримодальные paспределения со значениями, близкими $\mathrm{k} t=0,8$, 1,15 и 1,8 нм. Из этого также следует, что для цеолитов C-S, E-SLP и T-P узость распределения дифференциальных кривых адсорбции относительно мала по интенсивности и нерепрезентативна. Сравнивая значения полученной характерристической энергии адсорбции $\mathrm{E}_{0}$ исследуемых цеолитов, можно увидеть, что на $\mathrm{E}_{0}$ влияют не только разме- ры (диаметр пор Dp), но и химический состав цеолитов (содержание $\mathrm{Al}$ и вид обменных катионов), что приводит к модификации электрических полей в порах цеолитов.

\section{Заключение}

Полученные для данного набора природных клиноптилолитов результаты позволяют сделать следующие выводы. Закономерно, что изученные цеолиты показали соответствие их структуры и адсорбционных свойств известным HEU-материалам. Однако в изученных природных образцах в некоторых случаях уже присутствует природная мезопористость, аналогичная получаемой или специальными методами синтеза, или дополнительной пост-синтетической обработкой в синтетических аналогах клиноптилолита. Наличие элементов такой иерархической структуры позволяет предложить дополнительные области применения этих природных материалов, по сравнению с существующими в настоящее время, в т. ч. в медицине, гетерогенном катализе и ряде других.

Работа была поддержана VIEP и CUVyTT, в рамках исследовательской группы CA-95 «Investigación en zeolitas» (PROMEP-SEP, Mexico), проектом PAPIIT IN107817 (Мехісо), а также проектом № 4.5200.2017/БЧ Госзадания «Наука» Толского политехнического университета. Авторы выражают благодарность врачу-терапевту Дарье Владимировне Кулешовой за плодотворное обсуждение существующих перспектив применения природных клиноптилолитов в медицине.

\section{Информация об авторах}

Итиель-Эрнандес $\boldsymbol{\Gamma}$., PhD, научный сотрудник кафедры технологических процессов и гидравлики Столичного автономного университета Истапалапа.

Эрнандес M.A., PhD, научный сотрудник Исследовательского отдела цеолитов Автономного Университета Пуэбла.

Портильо P., PhD, научный сотрудник Факультета химических наук Автономного университета Пуэбла.

Петрановский В.П., $\mathrm{PhD}$, научный сотрудник Центра нанонаук и нанотехнологий Национального автономного университета Мексики.

Пестряков А.Н., доктор химических наук, профессор Школы химических и биомедицинских технологий Национального исследовательского Томского политехнического университета.

Рубио Э., PhD, научный сотрудник Автономного университета Пуэбла. 
UDC 549.08:549.67:544.02

\title{
HIERARCHICAL STRUCTURE OF NANOPOROSITY OF MEXICAN NATURAL ZEOLITES OF CLINOPTILOLITE TYPE
}

\author{
Gabriela Itzel-Hernández',
} gab.hdz.salgado@gmail.com

\section{Miguel Angel Hernández², vaga1957@gmail.com}

Roberto Portillo², portilloreyes@yahoo.com

\section{Vitalii P. Petranovskii,} vitalii@cnyn.unam.mx

\author{
Alexey N. Pestryakov4, \\ pestryakov2005@yandex.ru \\ Efraín Rubio², \\ efrain.rubio@correo.buap.mx \\ ${ }^{1}$ Metropolitan Autonomous University-Iztapalapa, \\ Av. San Rafael Atlixco No. 186, Col. Vicentina 09340 Iztapalapa, Mexico. \\ ${ }^{2}$ Meritorious Autonomous University of Puebla, \\ 4 sur 104, Centro Histórico, Puebla, 72000, Mexico. \\ ${ }^{3} \mathrm{CNyN}$, National Autonomous University of Mexico, \\ Km 107 Carretera Tijuana-Ensenada, Ensenada 22860, Baja California, Mexico. \\ ${ }^{4}$ National Research Tomsk Polytechnic University, \\ 30, Lenin Avenue, Tomsk 634050, Russia.
}

The relevance of the research is caused by the large number of newly discovered zeolite fields in Mexico. For practical use of these materials, the appropriate characteristics are required, in which experimental models are proposed that provide reliable and usable data for each of the declared deposits.

The main aim of this research work is to evaluate the adsorption capacity of natural clinoptilolite zeolites from different deposits in Mexico to assess their nanoporosity and to evaluate whether they have some mesoporous voids.

objects of the research are zeolite tuffs from seven different deposits located in Mexico. These deposits are poorly studied and characterized by a complex mineral composition of rocks.

Methods. Zeolites were studied by XRD, Scanning Electron Microscopy, energy dispersive spectroscopy, thermogravimetric methods and Differential scanning calorimetry. All samples were also studied by $N_{2}$ adsorption method. The surface areas of BET, Langmuir, and t-plots of all the investigated zeolites were estimated. The total pore volume was estimated in accordance with the Gurvitsch rule. The microporosity of these natural zeolites was measured using the DA high-resolution adsorption method. Information on the distribution of micropore sizes was obtained from the data of the isothermal adsorption-desorption.

Research results. The nanoporosity of natural clinoptilolite zeolites from new deposits is estimated using traditional experimental methods such as DRX, SEM, EDS and HRADS of $\mathrm{N}_{2}$ at the boiling point of liquid nitrogen. The latter method evaluates texture parameters, in which micropores are estimated by $t$-graphs. The nanopore distribution is determined using the recently proposed approximation, called differential adsorption curves. Studies of TGA and DSC show the presence of three types of adsorbed water: adsorbed water in macropores, water adsorbed in the outer region of zeolite (mesopores) and water adsorbed in micropores. This behavior was confirmed by $\mathrm{N}_{2}$ adsorption: microporous filling, multilayered formation on the outer surface of zeolite tuff, and the phenomenon of capillary condensation arising in macropores.

Key words:

Natural zeolite, clinoptilolite, characteristic adsorption energies, nanoporosity, mesoporosity.

The research was supported by the VIEP and CUVyTT, the Research Group «Investigacion en zeolitas», CA-95 (PROMEPSEP), Mexico, by the project PAPIIT IN107817, Mexico, as well as by the project no. 4.5200.2017/BP of the State Task «Science» of the Tomsk Polytechnic University. The authors express gratitude to the primary care Dr. Darya V. Kuleshova for productive discussion of the existing prospects in applying natural clinoptilolite in medicine. 


\section{СПИСОК ЛИТЕРАТУРЫ REFERENCES}

1. Wise W.S. Handbook of natural zeolites. Ed. by C. Colella. Napoli, De Frede Editore, 2013. 126 p.

2. Mumpton F.A. Reported occurrence of zeolites in sedimentary rocks of Mexico. American Mineralogist, 1960, vol. 58, pp. 287-290.

3. Hernández G., Hernández M.A., Portillo R., Salgado M.A., Rojas F., Petranovskii V. Properties of Nanoporosity of Clinoptilolite, Erionite, Epistilbite and Mordenite, natural zeolites from Mexico. Extended Abstracts of $18^{\text {th }}$ IZA Conference. Rio de Janeiro, Brazil, CD edition, 2016. PP84.

4. Hernandez M.A., Rojas F., Lara V.H. Nitrogen-sorption characterization of the microporous structure of clinoptilolite-type zeolites. Journal of Porous Materials, 2000, vol. 7, pp. 443-454.

5. Aguilar-Armenta G., Hernandez-Ramirez G., Flores-Loyola E., Ugarte-Castaneda A., Silva-Gonzalez R., Tabares-Munoz C., Jimenez-Lopez A., Rodriguez-Castellon E. Adsorption kinetics of $\mathrm{CO}_{2}, \mathrm{O}_{2}, \mathrm{~N}_{2}$, and $\mathrm{CH}_{4}$ in cation-exchanged clinoptilolite. Journal of Physical Chemistry B, 2001, vol. 105, pp. 1313-1319.

6. Hernández M.A., Rojas F., Corona L., Lara V.H., Portillo R., Salgado M.A., Petranovskii V. Evaluación de la porosidad de zeolitas naturales por medio de curvas diferenciales de adsorción. Revista Internacional de Contaminación Ambiental, 2005, vol. 21, pp. 71-81.

7. Hernandez V.A., Hernandez M.A., Quiroz K.F. Evaluation of nanopore size distribution by adsorption differential curves of clinoptilolite zeolites chemically modified. Mexican Journal of $\mathrm{Ma}$ terials Science and Engineering, 2016, vol. 3, pp. 49-53.

8. Mendoza A., Flores J., Flores M., Vidal J., Paz F. Estudio sobre la incorporación y retención de plomo en zeolita natural. UNI SON/Epistemus, 2014, vol. 17, pp. 16-22.

9. Kirov G., Filizova L. Cationic hydration impact on zeolite formation and properties: a review and discussion. Geochemistry, Mineralogy and Petrology, 2012, vol. 49, pp. 65-82.

10. Breck D.W. Zeolite Molecular sieves. Structure, chemistry and use. New York, John Wiley \& Sons, Inc., 1974. 234 p.

11. Liu M.F., Ottaviani L., Lei X., Turro N.J. Characterization of the external surface of silicalites employing electron paramagnetic resonance. Journal of Physical Chemistry A, 2004, vol. 108, pp. 8040-8047.

12. Martijn F.D., Vlugt T.J., Gascon J., Kapteijn F. Adsorptive characterization of porous solids: Error analysis guides the way. Mic roporous and Mesoporous Materials, 2014, vol. 200, pp. 199-215.

13. Colella C. Natural zeolites in environmentally friendly processes and applications. In: Porous materials in environmentally friendly processes. Studies in Surface Science and Catalysis, 1999, vol. 125 , pp. $641-655$.

14. Colella C. A critical reconsideration of biomedical and veterinary applications of natural zeolites. Clay Minerals, 2011, vol. 46, pp. 295-309.

15. Rodríguez G., Denis A.R., Barrios M.A., Colarte A.I. Antacid drug based on purified natural clinoptilolite. Microporous and Mesoporous Materials, 2006, vol. 94, pp. 200-207.

16. Pavelic K., Hadzija M., Bedrica L. Natural zeolite clinoptilolite: new adjuvant in anticancer therapy. Journal of Molecular Medicine, 2000, vol. 78, pp. 708-720.

17. Auerbach S., Corrado K.A., Dutta P.K. Handbook of zeolite science and technology. New York, Marcel Dekker, 2003. 212 p.

18. Cerria G., Gennaro M., de Bonferoni M.C., Caramella C. Zeolites in biomedical application: Zn-exchanged clinoptilolite-rich rock as active carrier for antibiotics in anti-acne topical therapy. Applied Clay Science, 2004, vol. 27, pp. 141-150.

19. Hernández M.A., Rojas F., Portillo R., Salgado M.A., Petranovskii V., Quiroz K. Textural properties of hybrid biomedical materials made from extracts of Tournefortia Hirsutissima L. imbibed and deposited on mesoporous and microporous materials. Journal of Nanomaterials, 2016, Article ID 1274817, $10 \mathrm{p}$.

20. Xu R., Pang W., Yu J., Huo Q., Chen J. Chemistry of zeolites and related porous materials: Synthesis and structure. Singapore, Wiley, 2009. $188 \mathrm{p}$.

21. Egeblad K., Christensen C.H., Kustova M., Christensen C.H. Templating mesoporous zeolites. Chemistry of Materials, 2008, vol. 20, pp. 946-960.

22. Groen J.C., Peffer L.A., Pérez J. Pore size determination in modified micro and mesoporous materials. Pitfalls and limitations in gas adsorption data analysis. Microporous and Mesoporous Materials, 2003, vol. 60, pp. 1-17.

23. Weber G., Simonot-Grange M.H. Characterization of the dealumination effect into $\mathrm{H}$-faujasites by adsorption: Part 2. The hexane molecule as a pore volume probe. Zeolites, 1994, vol. 14, pp. 433-438.

24. Hudec P., Smieskova P., Zidek Z., Schneider P., Solcova 0. Impact of zeolites and other porous materials on the new technologies at the beginning of the new millennium. Amsterdam, Elsevier, $2002.194 \mathrm{p}$.

25. Sing K., Williams R. The use of molecular probes for the characterization of nanoporous adsorbents. Particle \& Particle Systems Characterization, 2004, vol. 21, pp. 71-79.

26. Chen S.G., Yang R.T. Theoretical basis for the potential theory adsorption isotherms. The Dubinin-Radushkevich and DubininAstakhov equations. Langmuir, 1994, vol. 10, pp. 4244-4249.

27. Hernández M.A., Rojas F., Portillo R., Salgado M.A., Petranovskii V. Evaluación de la porosidad de zeolitas naturales por medio de curvas diferenciales de adsorción. Revista Internacional de Contaminacion Ambiental, 2005, vol. 21, pp. 71-81.

28. Alver B.E., Sakizci M., Yorukogullari E. Investigation of clinoptilolite rich natural zeolites from Turkey: a combined XRF, TG/DTG, DTA and DSC study. Journal of Thermal Analysis and Calorimetry, 2010, vol. 100, pp. 19-26.

29. Kennedy D.A., Tezel F.H. Cation exchange modification of clinoptilolite - Screening analysis for potential equilibrium and kinetic adsorption separations involving methane, nitrogen, and carbon dioxide. Microporous and Mesoporous Materials, 2018, vol. 262 , pp. 235-250.

30. Alver B.E., Esenli F. Acid treated mordenites as adsorbents of $\mathrm{C}_{2} \mathrm{H}_{4}$ and $\mathrm{H}_{2}$ gases, Microporous and Mesoporous Materials, 2017, vol. 244, pp. 67-73.

31. Knowlton G.D., White T.R., Mckague H.L. Thermal study of types of water associated with clinoptilolite. Clays and Clay Minerals, 1981, vol. 29, pp. 403-411.

32. Kustovska A.D. Adsorption of methanol and water vapor on modified forms of mordenite-clinoptilolite rock. Adsorption Science and Technology, 2018, vol. 36, pp. 927-935.

33. Thommes M., Kaneko K., Neimark A., Olivier J., Rodríguez F., Rouquerol J., Sing K.W. Physisorption of gases, with special reference to the evaluation of surface area and pore size distribution (IUPAC Technical Report). Pure and Applied Chemistry, 2015, vol. 87, pp. 1051-1069.

34. Hernández M.A., Rojas F., Lara V.H. Nitrogen-sorption characterization of the microporous structure of clinoptilolite-type zeolites. Journal of Porous Materials, 2000, vol. 7, pp. 443-454.

35. Mansoor E., Van der Mynsbrugge J., Head-Gordon M., Head-Gordon M., Bell A.T. Impact of long-range electrostatic and dispersive interactions on theoretical predictions of adsorption and catalysis in zeolites. Catalysis Today, 2018, vol. 312, pp. 51-65.

36. Akcley M.W., Rege S.U., Saxena H. Application of natural zeolites in the purification and separation of gases. Microporous and Mesoporous Materials, 2003, vol. 61, pp. 25-42.

Поступила 18.09.2018 г. Received: 18 September 2018. 
Information about the authors

Gabriela Itzel-Hernández, $\mathrm{PhD}$, researcher, Metropolitan Autonomous University-Iztapalapa.

Miguel Angel Hernández, PhD, researcher, Meritorious Autonomous University of Puebla.

Roberto Portillo, PhD, researcher, Meritorious Autonomous University of Puebla.

Vitalii P. Petranovskii, PhD, researcher, National Autonomous University of Mexico.

Alexey N. Pestryakov, Dr. Sc., professor, National Research Tomsk Polytechnic University.

Efraín Rubio, PhD, researcher, Meritorious Autonomous University of Puebla. 